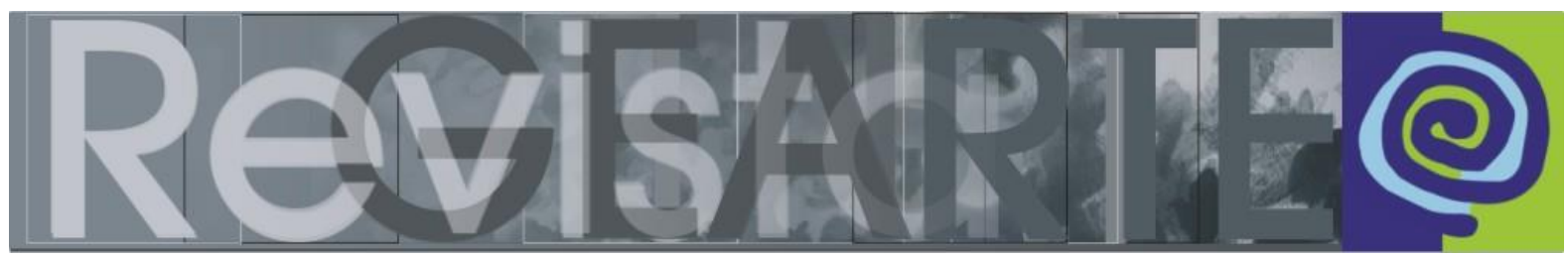

\title{
Abordaje Triangular desde un Episteme Decolonial
}

Ramón Cabrera Salort (Universidad Autónoma

de Nuevo León - UANL - Monterrey, México)

RESUMEN - Abordaje Triangular desde un Episteme Decolonial - Todas las artes pueden darse cita desde el episteme que devela el abordaje triangular, fruto de un sostenido bregar de Ana Mae Barbosa por el arte y el arte educación. Es asunto central del artículo analizar el abordaje triangular desde los estudios decoloniales y su concreción en la práctica educativa del autor.

\section{PALABRAS CLAVES}

Abordaje Triangular. Arte. Educación por el arte. Estudios decoloniales.

RESUMO - Abordagem Triangular desde uma Episteme Descolonial - Todas as artes podem ser referidas a partir da episteme que revela a Abordagem Triangular, resultado de uma posição que Ana Mae Barbosa tem sustentado pela arte e pela arte educação. A questão central do artigo está em analisar a Abordagem Triangular a partir dos estudos descoloniais e sua aplicação na prática educacional do autor.

\section{PALAVRAS-CHAVE}

Abordagem Triangular. Arte. Ensino da arte. Estudos descoloniais.

"Soy, donde pienso"

(Walter Mignolo)

Todas las artes pueden darse cita desde el episteme que devela el Abordaje Triangular, fruto de un sostenido bregar de Ana Mae Barbosa por el arte y el arte educación, encarnado en las más actuales corrientes de la Fenomenología Hermeneútica, de la Teoría de la Recepción, de la Semiótica, del Deconstruccionismo, del Feminismo y, añadiríamos nosotros, de los Estudios Decoloniales, en particular Freire desde la Pedagogía, sobre cuyos fundamentos se asienta.

La enumeración con la que inicia su La imagen en la enseñanza del arte es una evidente declaración de principios, no solo de aquellas peculiaridades que advierte dominan nuestra contemporaneidad, sino más allá de ello el convencimiento de que nuevos paradigmas y un episteme de cambio debe ser reconocido para practicar un arte/educación a la altura de nuestros tiempos. Esto es resultado indudable también de nuevos epistemes tanto para la ciencia como para las artes que desembocan en nuevas maneras de leer el mundo. $Y$ donde el concepto freireano de leer la palabra 
mundo alcanza inusitadas resonancias, que se fundamenta en los asuntos del texto en el vasto universo de las imágenes visuales. Así si en los avances en los dominios de la microfísica, de la química y de la biología hay una crisis del paradigma newtoniano como pauta del discurso acerca del método científico. Si un llya Prigogine con su teoría de las estructuras disipativas y el principio del "orden a través de las fluctuaciones" recurre a sistemas abiertos; sistemas en los márgenes de estabilidad, donde éstos evolucionan por fluctuaciones de energía, no enteramente previsibles, por mecanismos no lineales. Ello también va a tener su correlato en el ámbito de la producción simbólica de hoy con un acrecentamiento de las conceptualizaciones; un énfasis en las operaciones ideáticas; donde surge un universo imaginal asentado, como tendencia, en teorizaciones personales; caracterizado por construcción de "tesauros" como herramientas productivas; con una participación abierta de los saberes en lo: inter - multi - trans - disciplinario y donde para Latinoamérica esto llega a tener un ascendiente en lo político-social de resonancias propias inconfundibles. Esto último reconocerá Ana Mae cuando enfatiza:

Por isso temos, no Terceiro Mundo, que produzir nossas próprias pesquisas, nossas próprias análises e nossas próprias, ações para superar os preconceitos de classe existentes em nossos países, a respeito dos códigos culturais configuráveis (BARBOSA, 1998, p. 88).

Cuando la autora en este y otros textos suyos analiza obras cimeras de la modernidad europea, no deja de considerar a la par obras de nuestra América, en especial del Brasil. De igual modo hace eso con obras notables europeas pero que se hallan en museos brasileños, pues no solo cuentan los museos europeos o norteamericanos. Esto apunta, en cierto modo, a la necesidad de replantearse la historia, a reconocer la naturaleza incompleta o silenciada del modo de practicar y construir un sentido dominante de hacer historia del arte. Desde esa dimensión Ana Mae se nos perfila desde su ámbito de arte/educadora cercana a la corriente ya apuntada de pensadores decoloniales como Enrique Dussel, Walter Mignolo o Arturo Escobar. Recordemos que el epígrafe de análisis que escribió sobre lo que denominó como "aprendizaje triangular", en su libro Tópicos Utópicos, lo tituló Arte/educación poscolonialista en Brasil. 
Así un episteme latinoamericano para las Ciencias Sociales señalado por Maritza Montero y citado por Edgardo Lander destaca en su Abordaje, entre otras, por las siguientes ideas articuladoras de tal paradigma: la idea de liberación a través de la praxis, que supone la movilización de la conciencia, y un sentido crítico que lleva a la desnaturalización de las formas canónicas de aprehender construir-ser en el mundo; la redefinición del rol de investigador social, el reconocimiento del Otro como Sí Mismo y por lo tanto la del sujeto-objeto de la investigación como actor social y constructor de conocimiento; el carácter histórico, indeterminado, indefinido, no acabado y relativo del conocimiento; la multiplicidad de voces, de mundos de vida, la pluralidad epistémica; la perspectiva de la dependencia y luego, la de la resistencia; la tensión ente minorías y mayorías y los modos alternativos de hacer-conocer (LANDER, 2000).

Toda la extensa data de aplicación de lo que luego se constituyera en el abordaje o la propuesta triangular tuvo sus inicios no en peroraciones o elucubraciones teóricas, sino en la práctica cultural y educativa con las artes visuales y en las inmediatas repercusiones benéficas de tal praxis, claro que cimentadas teóricamente, pero revivificadas en su concreción social. Como buena discípula de Freire ella siempre ha reconocido que la cultura se asimila raigalmente en su práctica. Por eso reconoce su propuesta como la derivación de una doble triangulación, la primera de ellas de carácter epistemológico al reconocer al proceso de enseñanzaaprendizaje constituido por tres acciones fundamentales en lo mental y en lo sensorial: creación (hacer artístico), lectura de la obra de arte y contextualización; la segunda triangulación en la triple influencia de deglutir singularmente otros tres abordajes epistemológicos: su interpretación reflexivo-crítica de las Escuelas al Aire Libre mexicanas, el Critical Studies inglés y el Movimiento de Apreciación Estética ligado a la DBAE y todos ellos encarnados en un sostenido obrar con las imágenes artísticas (BARBOSA, 1998, p. 33-34).

Ese sentido en que refiere en más de una ocasión la deglución, es consecuencia en Ana Mae de su adopción del lenguaje antropofágico que proviene originariamente de Oswald de Andrade y que reconoce en la década de los 70 en el intelectual cubano Roberto Fernández Retamar con varios de sus ensayos, que hoy 
adscribiríamos como decoloniales. Esa acción de deglución se hace a la vez más presente en las artes visuales contemporáneas del continente que experimentan un rebasamiento de sus límites tradicionales, un perfundirse con otras artes, un planear sobre siglos y obras con afán de apropiación y un extenderse hacia las prácticas cotidianas más comunes y triviales o más abiertamente políticas y subversivas y menos implicadas o correlacionadas con el discurso de las artes. En un continente plagado de injusticias e inequidades no es difícil ser subversivo y lo subversivo, si el arte ofrece razones críticas y reflexivas de ser en el mundo, lo constituye.

A su vez la propia Ana Mae ha destacado cómo el abordaje no lo circunscribe al discurso del arte y cómo integra también a los variados componentes de la cultura visual contemporánea, en tanto el propio arte desde el pop los venía integrando, y también por el reconocimiento de los significados que cobran los medios masivos en los procesos de mediación de la cultura popular en nuestro continente. En nuestra cultura visual latinoamericana eso es algo que se venía dando en los procesos nuestros de mediación cultural como bien argumenta Martín Barbero desde su texto De los medios a las mediaciones.

Ana Mae precisará lo que argüimos para el proceso educativo de modo decolonial: "Arte e Cultura Visual devem conviver nos currículos e salas de aulas, suas imagens devam ser analisadas com o mesmo rigor critico para combatermos formas colonizadoras da mente e dos comportamentos" (BARBOSA, 2010, p. 22).

El hacer, dentro de las tres acciones constitutivas del abordaje, característicamente dominante en la enseñanza de las artes y, en particular, de las artes visuales, se encuentra en la concepción de Ana Mae, alejado de la asunción romántica de la creatividad incontaminada de lo espontáneo y de la búsqueda de originalidad a ultranza, donde el que aprende manifiesta en primer lugar su expresividad, sin ayuda de ningún otro recurso cultural. En contrapunto con esto para Ana Mae ese hacer requiere de un aprestamiento, del dominio de instrumentos culturales, proceso de "alfabetización" que supone siempre un hacer entrelazado con un leer y con un contextualizar. Por ello ese hacer con las imágenes en tanto hacer cultural, es intelectual también, tanto teórico como práctico. Muchos siglos atrás Miguel Angel había advertido que se pinta con el cerebro, no con la mano. Esta es 
otra manera en que el propio episteme que sustenta al abordaje triangular vuelve a la enseñanza de las imágenes artísticas en la escuela, no un asunto menor relegado a las manualidades, sino un complejo y activo movilizador de capacidades y competencias cognitivo/afectivas.

La lectura en su abordaje triangular, ligado a las teorías de la recepción y a los enfoques hermenéuticos y fenomenológicos, se reconoce como interpretación cultural y en esto advierte Ana Mae también la influencia de Paulo Freire. Quizá fuera preciso añadir que ese sentido de lectura tiene que ver con el concepto freireano de leer la palabra mundo de su La importancia de leer, con lo cual se alude a la metáfora de que lo primero que leemos es nuestro contexto. De aquí, entonces, la raigal relación entre lectura y contexto, pues como se reconoce desde su propuesta, situar la obra en contexto es propiciar el producir sentido en aquellos que la observan y ello se logra desde un campo de sentido decodificable y una poética personal del decodificador. Esto hace que tal lectura contextualizada opere para Ana Mae como cuestionamiento, como búsqueda, como descubrimiento, como acrecentamiento de la capacidad crítica y no únicamente como un aumento de la información acerca del arte, y donde las decodificaciones que opera el sujeto sobre una obra, comienzan por reconocer la necesidad de contar con un marco referencial de este sujeto para hacer posible el acto lector. La lectura se convierte en un acto de significación como comprometimiento, como apropiación cognitiva/afectiva, donde el yo lector dialoga con el tú de la obra visual.

Contextualizar será para ella sinónimo de tender puentes, establecer relaciones, reconocer nexos de carácter tanto históricos, como sociológicos, antropológicos, educativos, multiculturales, ecológicos. De ahí que la contextualización en el proceso de enseñanza-aprendizaje se constituya en fundamento de la interdisciplinariedad y resulte de tal modo una cognición situada, construida socialmente por sujetos y, por lo mismo, significativa para ellos. A lo largo de todo el libro estará aplicando la contextualización en tal sentido, ya sea cuando argumente su abordaje triangular, como cuando analice las diferentes metodologías a la luz de la DBAE en Norteamérica o ilustre el rol de los museos y los educadores dentro de él en la misión de educar a través del arte. De tal aplicación es que sabrá 
destacar lo notable o lo errado, pues realiza análisis de situaciones concretas desde sus especificidades, nunca haciendo traslados mecánicos, ni tomando como paradigma un modo único de concebir el complejo y personalizado proceso de la enseñanza-aprendizaje de las artes visuales.

Por esa razón, la triangulación de su abordaje no significa reconocer una jerarquía en las acciones, sino por el contrario la naturaleza aleatoria de la secuencia de tales acciones, lo que supone que en un caso el proceso puede iniciar con la lectura y luego proseguirse con el hacer, concibiendo ambas acciones en el escenario de su contextualización, o en otro momento variar por completo tal secuencia. Por otra parte, no advertir jerarquías entre ellas viene dado, además, por la naturaleza epistémica de la urdimbre que las constituye, ya que una acción implica a las otras, no son acciones susceptibles de separación formal sin que con ello no quede afectada o desnaturalizada la complejidad constitutiva que la asiste. Esta es una cualidad que la cultura latinoamericana exhibe de modo "natural" y que ha dado lugar en el discurso de muchos teóricos nuestros, García Canclini, por ejemplo, la aparición del calificativo de hibrido o hibridez para distinguir especificidades contemporáneas de lo propio (GARCÍA CANCLINI ,1992).

Precisamente Ana Mae al analizar diferentes metodologías del proceso de enseñanza-aprendizaje con obras de artes visuales confirma cómo esa resulta ser una de las fallas más comunes: el convertir lo que debiera ser un diálogo vivo e irrepetible, en un conjunto preestablecido de pasos que ordena y acata un algoritmo de procedimientos. También al analizar esas metodologías destaca, en el caso del Método Multipropósito de Robert Saunders desde la DBAE, a la par que las bondades que puedan desgajarse de los argumentos de este autor para propiciar las lecturas de las obras de arte, la limitación de ofrecer soluciones sobre cómo leer, pero sin advertir que junto a ello deben suscitarse problematizaciones, situaciones problematizadoras que se convirtieran en retos interpretativos para los escolares. En mi experiencia de arte/educador he podido comprobar lo usual que resulta caer en esa trampa de acatar, por costumbre o rutina, un modelo secuenciado de acciones en el proceso de enseñanza-aprendizaje del arte $u$ ofrecer ejemplos de cómo efectuar una buena lectura, pero sin considerar debidamente el alto contenido movilizador cognitivo y 
afectivo de problematizaciones que no pueden surgir en un escenario de acciones artificialmente escindidas. Leer es un modo de hacer, al igual que al momento de hacer leemos y en ambas se manifiesta la razón de su existir en contexto.

Es precisamente la contextualización la acción generadora que Ana Mae señala como la dinamizadora por excelencia del abordaje, que llega a reconocer trascendiendo la figura del triángulo. De ahí que ella misma confesara: "Parece-nos mais adequado representá-la pela figura do ziguezague, pois os professores nos têm ensinado o valor da contextualização tanto para fazer como para o ver" (BARBOSA, 2012, p. XXXIII).

La contextualización alcanza en el pensamiento decolonial una doble dimensión: epistémica e histórica. Epistémica en el sentido que incide tanto en los modos de saber, como de conocer e histórica porque nos identificamos y definimos a partir de Europa, de ahí la denominación dominante de "América precolombina" donde en verdad habría de hablarse de América Antigua, pues nuestros pueblos originarios tuvieron también su antigüedad de distinta naturaleza y composición que la del Occidente. Ya lo advertía José Martí en el siglo XIX: "La historia de América, de los incas acá, ha de enseñarse al dedillo, aunque no se enseñe la de los arcontes de Grecia. Nuestra Grecia es preferible al Grecia que no es nuestra. Nos es más necesaria" (MARTí, 1963, p. 18).

Para el pensamiento decolonial resulta seminal señalar que la primera descolonialización (iniciada en el siglo XIX por las colonias españolas y seguida en el $X X$ por las colonias inglesas y francesas) fue incompleta, ya que se limitó a la independencia jurídico-política de las periferias. En cambio, la segunda descolonialización - a la cual se alude con la categoría decolonialidad - remite a las múltiples relaciones raciales, étnicas, sexuales, epistémicas, económicas y de género que la primera descolonialización dejó intactas y que la decolonialidad encamina a los procesos mediante los cuales quienes no aceptan a ser dominados y controlados no solo trabajan para desprenderse de la colonialidad, sino también para construir modelos no manejables y controlables por esa matriz (MIGNOLO, 2012). El abordaje triangular se inscribe desde una pedagogía crítica y liberadora en una modalidad que se asume para todo tipo de discurso simbólico, en el más extendido registro de lo 
sensible en razón de contextos propios donde confluye nuestra pluri-culturalidad y donde el sentido del contexto es tanto territorial e histórico como epistémico.

\section{Contextualización personal}

Ana Mae lo decía "não é falar sobre uma pintura, mas falar a pintura" (BARBOSA, 2012, p. 20). Y ese hacer hablar a las imágenes visuales pasa por todo el cuerpo y por todos nuestros analizadores y por la acción combinada de construir ${ }^{1}$ imágenes que implica a la vez su lectura y su cristalización en contexto.

Desde 1995 cuando elaboré una Maestría en Educación por el Arte, primero para el Instituto Superior de Arte, en La Habana, y luego como Maestría en Arte para la Universidad Autónoma de Nuevo León, en Monterrey, en 1997, en las disciplinas de posgrados de ambas, relativas a Teorías y teóricos de Educación por el Arte y a Didáctica de la Imagen, los textos de la educadora Ana Mae Barbosa, eran bibliografía obligada junto al de otros teóricos como Elliot Eisner, Rudolf Arnheim o Howard Gardner, por citar algunos, y en especial, su concepción del Abordaje Triangular. Las concepciones de Ana Mae, su preocupación por la historia y su manera acuciosa de practicarla para el arte/educación, amén del mencionado abordaje que se nutre de esa historia, siempre han aportado junto a las luminarias experiencias del cono sur de las hermanas Cossettini, Jesualdo y Luis F. Iglesias, o las del mexicano Víctor M. Reyes o las del español Gabriel García Maroto, tanto en México, como en Cuba, el sesgo de lo propio. Amén de ello, tanto en investigaciones de tesis de maestría en Educación por el Arte asesoradas por mí en el último lustro, como en experiencias artístico/pedagógicas de más larga data en la formación profesional de artistas visuales, en el Instituto Superior de Arte, es posible advertir el abordaje triangular. En la tesis de maestría de Maikel Rodríguez de la Cruz (2013) aplicada a su materia de Escritura escénica, donde en el entrecruzamiento de las artes plásticas, la literatura, la música y la historia, encarnado en su Sistema de Acción Texto Abierto, el abordaje cobra sentido, o en la tesis de David Ramírez Larsen, donde el abordaje se hace

1 Construir en el sentido en que la artista y educadora brasileña Lucimar Bello emplea un neologismo para calificar los fundamentos sobre los que se asentaba su proyecto educativo en arte: "constructivación" (construcción en la acción), "intentando romper con lo convencional, quiero decir, intentando crear rupturas con las reglas ya establecidas" (FRANGE, 2010, p. 117). 
manifiesto en el modo en que se labora con las imágenes tanto para un curso de Expresión digital como de Creatividad en Diseño Digital, en preparatorias regiomontanas. El propio David suscribe su bregar indagatorio del siguiente modo:

Durante todo el primer semestre del año, y las vacaciones de verano, trabajé, quizás con más profundidad de la necesaria, en el marco teórico de la tesis. Pronto me di cuenta que los conceptos que había contemplado para mi tema anterior, no eran los únicos presentes en ambos cursos. A la visión multidisciplinar, la relación entre el hacer y el ver arte, y el fomento de la continuidad, se le habían sumado, por lo menos, el contexto, el incremento del protagonismo del alumno, y la inclusión de la obra de arte o diseño profesional en el aula (RAMÍREZ LARSEN, 2016, p. 3-4). ${ }^{2}$

En razón de ilustrar con ejemplos de excelente desempeño curricular en la formación universitaria de profesionales de la visualidad, donde el abordaje se hace manifiesto desde una doble articulación tanto de naturaleza pedagógica como creativa y, por lo mismo, como demostrativo de su razón de ser como episteme del arte y de su enseñanza, en el sentido que argumenta Ana Mae:

Quando falo de conhecer arte, falo de um conhecimento que nas artes visuais se organiza inter-relacionando o fazer artístico, a apreciação da arte e a história da arte. Nenhuma das três áreas sozinha corresponde à epistemologia da arte. O conhecimento em artes se dá na interseção da experimentação, da decodificação e da informação (BARBOSA, 2012, p. 33).

Tomo en consideración el conocimiento del arte y el entrecruzamiento de estas acciones seminales de experimentación, de información y de decodificación, en los proyectos grupales que se sucedieron en la Facultad de Artes Plásticas del ISA (La Habana), de 1997 al 2004, con una breve incursión en otros ejemplos puntuales más cercanos en el tiempo, efectuados dentro la fructífera experiencia de Medios Múltiples en la UNAM, en Ciudad México. En todos ellos se pusieron de manifiesto complejas y sistemáticas interrelaciones de armonización entre los sujetos participantes, interacciones presididas por el debate franco y abierto resueltas en decisiones creativas grupales, pobladas de acciones simbólicas de plural naturaleza y de singular arraigo en el campo cultural y educativo de mi país. En todos ellos es altamente revelador el modo en que se hallan entrelazados el hacer, el leer y el contextualizar,

2 El subrayado es mío. La tesis se titula La creación y el análisis desde la integración, la continuidad y el contexto. Experiencias tempranas en la educación artística a nivel medio superior. Facultad de Artes Visuales, UANL, Monterrey, 2016. 
aunque en su momento no hayan sido identificados de tal manera o no se hayan advertido con el grado de conciencia que hoy pongo de manifiesto.

Tales logros son en buena medida el resultado de una estrecha integración de los talleres con las teorizaciones o, para decirlo con mayor exactitud, una exigencia de la práctica artística para alcanzar un sólido basamento; una comprensión cabal de los complejos procesos de mediación en los cuales una práctica cultural cualquiera se halla contenida y, por tanto, el convencimiento de que la formación profesional no es solo la de un 'hacedor` de imágenes, sino la de un intelectual que problematiza y reflexiona críticamente sus medios, sus modos y sus fines de socialización de obra, donde no es posible, a la par, concebir un proceso público con tales imágenes sino despierta parejos cuestionamientos y aprestamientos en el espectador, de donde vuelve a manifestarse la pertinencia del abordaje triangular, que concita un esfuerzo cognitivo/afectivo de desentrañamiento y fruición situado.

Las artes visuales en nuestro continente realizada por grupos de creación o por creadores que apuestan con más insistencia a socializar sus operaciones no en los sitios, ni desde los reclamos consagrados por el mainstream, sino en ámbitos comunitarios del más democrático acceso, como hace el grupo Bijari, en Brasil, por ejemplo, o Jimena Hernández con proyectos comunitarios en la región de Medellín, en Colombia, exhiben un discurso donde lo popular y lo culto, ejercicios reflexivos críticos sobre condiciones de vida en planos de socialización compartida, se confunden y constituyen un modo singular de ver mezcladas imágenes de los más encontrados orígenes. El Abordaje Triangular se muestra, entonces, tanto en manos de artistas, de educadores, de educandos y de todo público, como una excelente herramienta para hacer que el ojo salte el muro de la mansedumbre, de las miradas complacientes, del pensamiento domesticado, de los sentidos adormecidos y compartimentados y devele un nuevo modo de estar y fruir en el mundo. Desde una realidad que se muestre propia, propiedad en el sentido martiano del término, quien desde el siglo XIX supo advertir que "no hay batalla entre la civilización y la barbarie, sino entre la falsa erudición y la naturaleza" (MARTí, 1963, p. 17). 


\section{Referencias}

BARBOSA, Ana Mae. Tópicos utópicos. Belo Horizonte: C/ARTE, 1998.

BARBOSA, Ana Mae. A imagen no ensino da arte. Sâo Paulo: Editora Perspectiva, 2012.

BARBOSA, Ana Mae; CUNHA, Fernanda Pereira da (Org.). Abordagem Triangular no ensino das artes e culturas visuais. São Paulo: Cortez Editora, 2010.

CABRERA SALORT, Ramón. Paulo Freire y Pichon Rivière en los cauces del ISA. In: CABRERA SALORT, Ramón (Org.). Indagaciones sobre arte y educación. La Habana: Editorial Adagio, 2010. p. 267-281.

CANCLINI, Néstor García. Las culturas híbridas: estrategias para entrar y salir de la modernidad. México: Siglo XXI Editores, 1992.

FRANGE, Lucimar Bello Pereira. Por que se esconde a violeta. São Paulo: Annablume Editora, 2010.

LANDER, Edgardo (Org.). La colonialidad del saber: eurocentrismo y ciencias sociales. Perspectivas latinoamericanas. Caracas: CLACSO, 2000.

MARTí, José. Nuestra América. v. 6. Obras Completas. La Habana: Editorial Nacional de Cuba, 1963. p. 15-23.

MARTÍN BARBERO, Jesús. De los medios a las mediaciones: comunicación, cultura y hegemonía. México: Editorial Gustavo Gili S. A., 1987.

MIGNOLO, Walter; GÓMEZ, Pedro Pablo. Estéticas y opción decolonial. Bogotá: Universidad Distrital Francisco José de Caldas, 2012.

RAMÍREZ LARSEN, David A. La creación y el análisis desde la relación, la continuidad, el contexto y el protagonismo del alumno. Tesis (Maestría en Educación por el Arte) - Facultad de Artes Visuales, Universidad Autónoma de Nuevo León, Monterrey. 2016.

RODRÍGUEZ DE LA CRUZ, Maikel. S.A.T.A. Provocaciones para la escritura escénica. Tesis (Maestría en Educación por el Arte) - Facultad de Artes Visuales, Universidad de las Artes (ISA), La Habana. 2013.

\section{Ramón Cabrera Salort}

Es doctor en Ciencias Pedagógicas en Arte por el Instituto de Investigaciones Científicas de Educación Artística, en Moscou, 1985. Licenciado en Historia del Arte por la Universidad de la Havana (1972). Autor de innumerables textos sobre educación artística. Fue Coordinador General de la Maestría en Educación Artística del Instituto Superior de Arte (ISA), desde su creación en 1995. Actua como profesor invitado em la Facultad de Artes Visuales de la Universidad Autónoma de Nuevo León, Monterrey, México, desde 1992. Fue el primero secretario adjunto del Consejo Latinoamericano de Educación por el Arte (CLEA) y miembro de la Asociación Internacional de Críticos de Arte (AICA), da Sección de Teoría e Crítica de la Unión Nacional de Escritores de Cuba (UNEAC).

E-mail: casalort@cubarte.cult.cu

Currículo: http://www.unesco.org/fileadmin/MULTIMEDIA/HQ/CLT/pdf/theme3bioramoncabreraen.pdf

Recebido em 28 de janeiro de 2017 Aceito em 22 de abril de 2017 